\title{
Dendrochronology of U.S. immigration
}

Keywords: information visualization, data visualization, information design, data art, graphic design,

figurative metaphors

Immigrants are central to the identity of the United States, the population of which has grown in number and diversity as a function of new arrivals from around the globe. This article describes a visualization project that uses the visual metaphor of tree rings to explore the contribution of immigrants to the country's population. Immigrants and native-born persons are represented and differentiated as cells in trees, with layered annual rings capturing patterns of population growth. These rings register, in their shape and color, certain environmental conditions. In order to mimic the natural process by which growth rings are formed, we devised a computational system that simulates the growth of trees as if cells were data-units. Dendrochronology involves dating certain events by analyzing patterns of growth in trees.

Analogously, in our visualizations the rings can be counted and dated, showing the chronological evolution of the population. The dendrochronology theme is a poetic take on the data, yet it is also a functional and conceptual space that is used to construct language and rationales on that data. The tree-growth process not only inspires the appearance of the visualizations but also informs the rules of the computational system that creates them.

\section{Introduction}

This project came about as a creative response to rising anti-immigrant sentiment in the United States in the wake of the 2016 presidential election. This sentiment has translated into public policy proposals, including: attempts to build an extensive wall at the U.S.-Mexican border; restrictions on the H1-B program, which allows foreign nationals to work in the U.S.; and attempts to overturn the Deferred Action for Childhood Arrivals (DACA) program, which has served to provide security to persons who were brought to America as children by their parents without full authorization. In light of this contentious and vitriolic political context, this project attempts to recast immigration in the American context in a more celebratory and poetic light, mining the vast history of immigration in the country to generate new meanings and framings. We do this through a series of data-driven pieces that leverage visual metaphor but which are rooted in rigorous algorithmic processing of public administrative data.

Immigration has been present in the United States since its inception and thus is central to the identity of the country. Waves of immigrants from around the globe have shaped the country's population. In the first stage, this work makes visible this fundamental historical pattern and phenomenon-that immigration 
has had a pronounced impact on population growth. To do this, the project shows how much immigration has increased in contrast with the number of national newborns, instead of showing immigrants as a percentage of the whole population. In other words, the project shows the number of people added to the population in a given time period (i.e., the growth of population). The evolution of national newborns (or as we label them, "native-borns"), together with incoming waves of immigrants, is visualized for each of the 50 U.S. states individually. These depictions use the metaphor of tree rings to provide visual structure to the data while casting an integrative light on the theme. The rationale behind choosing such a metaphor is detailed in this paper.

In the second stage, this work focuses exclusively on immigration, enabling a clearer portrayal of waves of immigration into the country as a whole, and also into each one of the states. As will be explained, several design options resulted in each state having a well-marked visual representation, thus conferring a unique identity to each one of them.

\section{Related approaches}

Simulating natural systems inspired in nature in order to visually organize information is a well-known approach. One example of a physically inspired system is graph drawing by force-directed placement (Fruchterman \& Reynolds 1991), where edges function like springs and nodes repel each other based on nuclear forces. When simulating such a system, it is possible to automatically draw complex graphs in a way that makes their structure legible, while providing a myriad of equally optimal solutions. Additionally, these systems can also be biologically-inspired, which is the case for information flocking. Information flocking (Vande Moere \& Lau 2007) is inspired in the behavior of flocks of birds, or schools of fish, in order to represent time-varying datasets. This is attained by exploring the emergent property of self-organization of these systems. These examples simulate natural phenomena as a way to solve general classes of visualization problems, but do not address any specific dataset from neither a rhetoric nor an expressive perspective.

The presence of nature-inspired visuals and metaphors is frequent in visualization as a way to connect with audiences in impactful ways. Poppies have been used to show conflicts during the First World War, as they became a symbol of remembrance and hope (D’Efilippo \& Ball 2016). Additionally, tree rings have been used to display statements and images of Emily Carr's work in a museum setting (Hinrichs, Schmidt, \& Carpendale 2008). In that work, a cross-section of a tree is used to organize information chronologically, and can be interacted with by selecting from many circles inside each ring. The authors chose this metaphor to render their artistic perspective on the most pervasive themes in Carr's work. Both works apply visual metaphors in a way that evokes data-related contexts and themes. Each chosen metaphor translates the authors' rhetorical intent, while enabling the resulting visualizations to be more expressive, more familiar, and more impactful. The visual forms that were utilized, are nature-inspired, but are not derived from a simulated system that mimics the behavior of a natural-object. This results in renditions that are often simplified interpretations or caricatures of the natural-objects. Furthermore, they are not strictly derived and built from data, but instead fit the data into interpreted visual conventions.

Our approach integrates these two types of applications of natural systems as metaphors to visualization: simulating the very own natural-system by data stimulation, and having as the simulation result, a visual rendering of data-packing structures that immediately resemble the natural-system that originated it. This means that form is derived both from data and nature. 
While the system is simulated in order to spatially present and organize data, the resulting rendering is used for rhetorics on data themes and framings. A previous work that implemented this approach shows traffic flowing through a series of interconnected arteries in a city as a beating heart (Cruz \& Machado 2016). In that work, expansions and contractions show rush hours, the arteries pulse to the rhythm of traffic on roads, and circulating cells travel in a speed proportional to the vehicles they represent.

\section{Tree rings for immigration}

As previously mentioned, this work is data-driven. This means that the resulting visualizations have the potential to show patterns and support facts, and with that, carry their own persuasive power. For this, we used historical data that describe how the country evolved in terms of immigration. The forms that we developed related, at a variety of levels, to the concepts of identity, diversity, inclusiveness, and regeneration. Overall, the project posits the concept of a country as a living organism. Indeed, such organism has been alive for a long time, and it slowly grew from immigration.

In order to show the data, we integrated an explicit and visible metaphor as a way to embed in the visualizations our own rhetorics and framings relating to immigration. The visual application of the metaphor also serves the purpose to confer the data with a familiar form, which has the potential of making it both more engaging and accessible to a broad audience. Furthermore, the metaphor serves not only these high-level communication perspectives, but it also provides a strict organization to the data in a visual form. This organization is done in such a way as to enable the decoding of data-driven information through the aide of metaphor, allowing the reader to interpret using this visual-intellectual framework.
We chose the metaphor of tree rings for this data and theme (Figure 1). Tree rings are the circular marks seen in a tree's trunk when it is cut. They are made of cells that multiplied and died. The growth rate of these cells varies throughout the seasons, resulting in the visible marks that are the tree rings. They generally mark one-year periods of growth, and the thickness of the ring can tell how much the tree has grown in a year (Fahn, Burley, Longman, \& Mariaux 1981). The idea of perennial growth, engendering life itself, is embodied in these marks. Trees can be hundreds, even thousands years old; the cells grow slowly, and their pattern of growth influences the shape of the tree's trunk. The cells and rings are the result of a slow process that occurred a long time ago. With these notions, tree rings lend themselves to

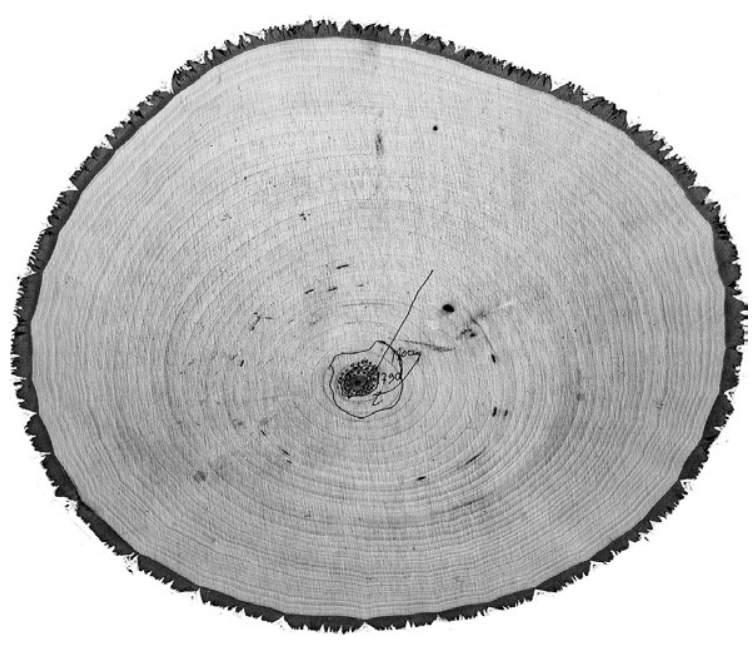

Figure 1. A cross section of American basswood (Tilia americana) is shown here. This cross section served as reference throughout the process. It can be observed that tree rings can be tenuous, that they vary in thickness, and that they are not perfect circles. In fact most of the rings appear to be concave, but some can be convex as well as clearly seen by the bark's outline. 
the representation of history itself, showing a sequence of events that have left a mark and shaped the present. Cells represent both immigrants and native-borns, who together contribute to the trunk that is America. They left marks that solidified inside the trunk. This suggests the notion that these marks are immutable and cannot be erased, regardless of how you read them; they are an instrumental antithesis to immigration revisionism, racial nationalism, and isolationism. Additionally, these marks carry this idea of identity, diversity, and inclusiveness: all cells are different, but all of them contributed to the organism's growth, being all part of it, and contributing to the formation of a unique entity.

The cells and rings in a tree constitute nature's own way of organizing information. By replicating its organizational strategies, we can also visually structure a dataset for presentation. With this, we are visualizing complex data through an organized structure. We use a natural structure because it already provides solutions that embed complexity in order. This approach is in line with our perspective on information visualization, and in line with Manovich's direct visualization approach (Manovich 2011): making the data itself visible in all its possible granularity, as much as the visual informational bandwidth of the medium enables-and as much as our cognitive systems enable. This means that, as much as possible, all datapoints should be made visible, revealing the complexity of the dataset. These datapoints, however, should be organized in such a way that reveals patterns in that same data.

Therefore, we designed and implemented a system based on nature's solutions for encoding information. Such an approach provides functionality at many levels: structural, as a way of organizing information; and communicational, as a way to convey not only data patterns but also our own rhetorics and themes. It should also be added that rhetoric here is not gratuitous or decorative, but strictly connected with the semantics of the data itself (Cruz 2015). More formally, we are implementing a metaphor that enables the understanding of the data domain in terms of the natural domain, while creating new meanings that are semantically dependent on the data.

The concept of creating a "living" visualization is crucial. For this, we computationally simulate how a tree grows naturally with a series of simplifications, instead of just laying out the data in a way that resembles the forms that are usually seen in tree rings. This is the strategy that provides the most reliable results in terms of appearance while also legitimizing the approach; the argument is that it was indeed data itself that made the tree grow, given a series of rules. We therefore have a system that simulates natural phenomena as stimulated by data, and a system that at the same type adapts to data. Because a tree can grow in many ways, having a system that also provides for non-deterministic outcomes results in the production of visuals that can have varying degrees of expressiveness, while telling the same story.

This approach to organizing visual space, borrowed from nature, results in visualizations that are highly functional and in densely compacted information in visual structures, enabling the decoding of that same information. Given this utilitarian view of the visualizations, and the fact that they simulate how a tree grows, we used the term "simulated dendrochronology" in order to describe it. Dendrochronology, coming from dendron (tree), chronos (time), and logos (the science of), is the science that uses tree rings dated to their exact year of formation to analyze temporal and spatial patterns of processes in the physical and cultural sciences.

\section{Data}

The dataset we used was extracted from the Integrated Public Use Microdata Series (IPUMs) (Ruggles et al. 2018). This data consists of micro-data for census 
questionnaires from all of the U.S. Census since 1790. It should be noted that a large number of territories were only incorporated as states after 1790 , meaning that data for these states was only available after a certain year. Results from the census are decennial and thus our tree rings will not grow year by year, but instead decade by decade until we reach the last census of 2010. In order to bring the visualization to more recent years, we also added data from the 2016 American Community Survey (ACS) so that we could extrapolate our quantities for 2016. The micro-data comes in different quantities for each decade. We are provided with a sample of answers to census and Acs questionnaires, which can vary from $1 \%$ to $100 \%$. The data also indicated representativeness: for each person reported, it is useful to know how many persons in the U.S. population are represented by that given person in the sample. This enabled us to extract the total counts of population and groups across the years. Taken together, the data collected and processed constituted more than 2 billion entries. In order to infer immigration, we referred to the place of birth of each person, which originally consisted of 571 different denominations/origin locations. Using these groups, we looked at how the population of each group varied so that we could compute estimates of arrivals of persons from that specific group: if the population count of a group increased from one decade to the other, then these persons were considered immigrants. We computed the total of native-borns through time using a similar method, focusing on persons less than 10 years old who had a U.S. place of birth. Our results were comparable to official census statistics, both for the native-borns and for the number of immigrants (when available). After reviewing the data, these places of origin were classified into seven cultural-geographical groups: Canada, Europe, Latin America, Asia, Oceania, Africa, and the Middle East. Colors were assigned to differentiate these groups.

\section{Rules and implementation}

This section details the science and biology behind tree rings, as well as which scientific elements inspired the algorithm that makes our data-trees grow. A tree ring can also be called a "growth ring." In a cross section of the stem of a woody plant, a growth ring is formed by the increment of wood added during a single growth period. In temperate regions, the growth period is usually one year, in which case the growth ring may be called an annual ring. In tropical regions, growth rings may be rendered invisible, as the seasons do not change as much as in temperate climates. Nonetheless, because most of the U.S. has a temperate climate we can proceed with using visible tree rings. Growth rings are distinct, depending on whether the cells were produced early in the growth period, or later. Early produced cells tend to be larger, and are called spring wood or early wood; and cells produced later tend to be smaller, and are called summer wood or late wood). Growth is terminated by a layer of relatively thick-walled fibers. This is what confers the tree rings their most prominent dividing mark. This mark is accompanied by a set of always-diminishing cells, which creates an increase in density as one gets closer to the thick-walled fibers (Figure 2). This means that the growth process is not just separated by a line, but also integrates a gradient of increasing density that eventually culminates in such division (Fahn et al. 1981; Kim, Funada, \& Adya 2016).

A tree's trunk is rarely made of concentric circles. These circles vary in size and thickness according to environmental conditions. Trees can respond to these conditions in several ways. One physiological way is what is called "reaction wood" in which a tree can produce more wood cells in a certain direction if it is tilting that direction in order to support its weight (Donaldson \& Singh 2016). By observing how rings progressed in terms of thickness, we identified that a Gaussian curve, 


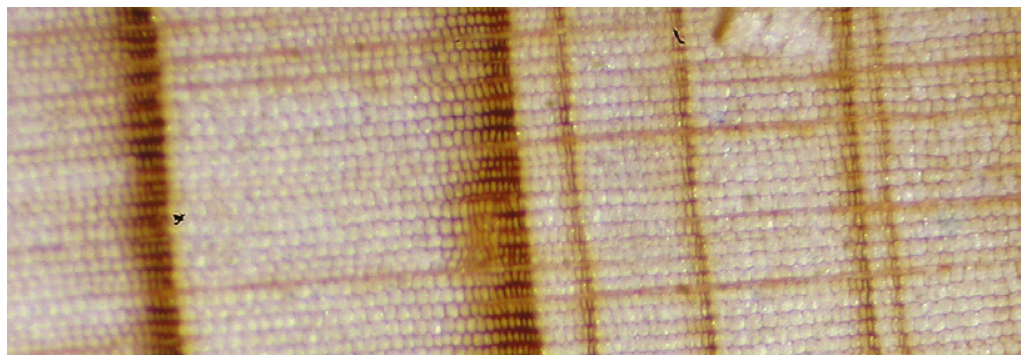

Figure 2. Tree cells being more compressed as they grow. The dark bands show division between one tree ring and the next. Image by Peter Brown/ Rocky Mountain Tree-Ring Research, used with permission.

with a fairly high standard deviation, could be used to describe these shapes, as seen in Figure 3. In fact, if we imagined one of these tree rings unfolded over a straight line, such a Gaussian curve would be made visible.

The main idea behind the algorithm is, simply put, to simulate how a tree grows. For this, instead of starting with a set of rings or circles, and distorting them in order to resemble tree rings, a set of dots are placed in space as if they were the cells of a tree. The rules that dictate such placement should result in a graphical arrangement that as an aggregate resembles the cross section of a tree trunk. No two cells can occupy the same physical space. Therefore, the dots also obey this constraint; and they can push among each other in order to make space in case they overlap. One property of the algorithm is the minimum spacing between points. If two points are closer than the minimum spacing, they are considered to be overlapping and thus a cascade of algorithmic pushes is enacted until the minimum space constraint is resolved.

It should also be noted that tree cells originate in the vascular cambium, a layer of cells just below the bark (Figure 4). This is an important property since when new cells are born, the pressure from the cells that were already there and the pressure from the bark compact them into smooth shapes. In order to mimic this behavior, our algorithm makes new cells appear just a couple of layers below the more recent layers of cells that had been already formed.

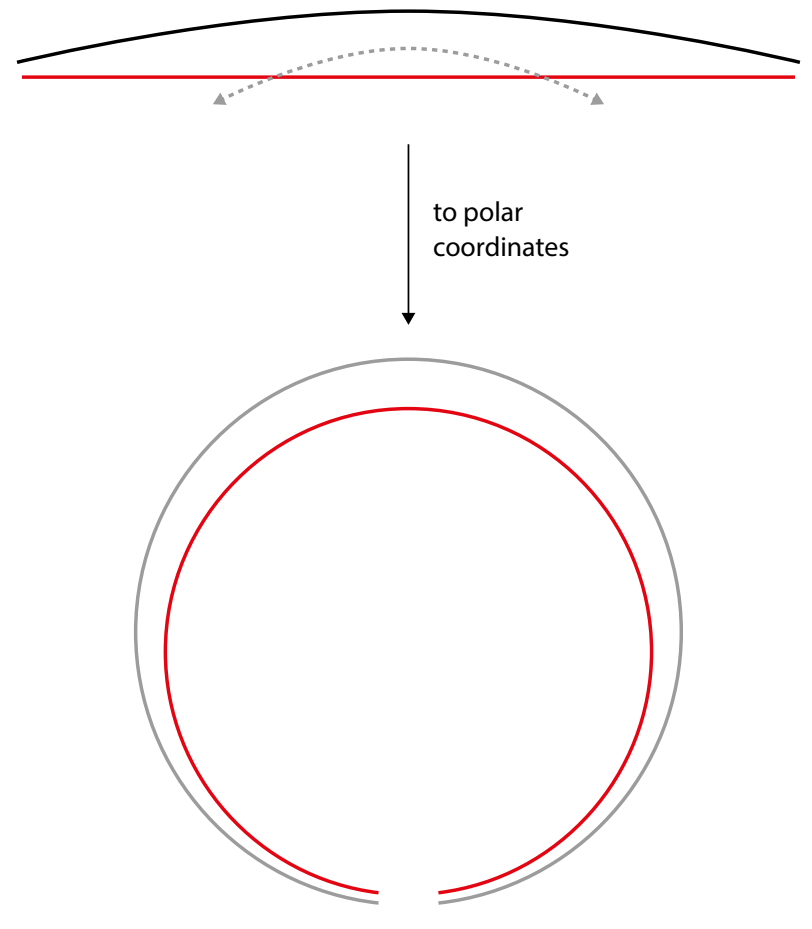

Figure 3. A Gaussian curve transformed into polar coordinates as to represent when it is folded into itself. The resulting configuration resembles a tree ring that varies in thickness following a profile that we often observed in tree rings. 


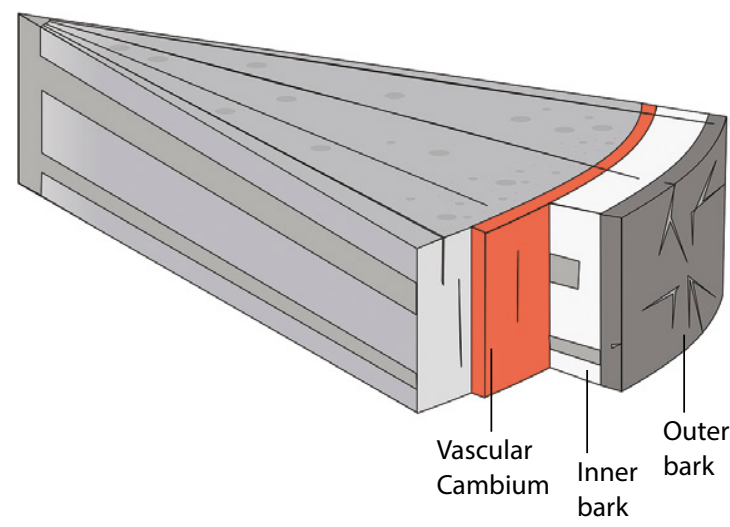

Figure 4. "Cross section through a 5 year old Pine Trunk" by Thomas Steiner licensed under CC BY-SA 3.0.

In this project, we had to consider that U.S. immigrants come from several geographical directions. To encode this variable, we decided to represent these different geographical migration vectors by making our data tree rings grow in the direction from which immigrants arrive (e.g., Latin America, Asia, Europe, etc.). This mimics the natural phenomenon of reaction wood, a physiological response from the tree. It is as if immigrants were adding weight to the tree and pushing it in a certain direction. In order to make the tree grow more in certain directions depending on immigrants' places of origin, these seven cultural-geographical groups were attributed to specific directions and color (e.g., Canada $\nabla$ North, Europe $\nabla$ East, Latin America $\nabla$ South, and so on). With these directions, a Gaussian distribution was created for each immigration group, with the average centered on the attributed direction (Figure 5). This Gaussian distribution is the probability model that determines where a certain cell will be placed. This means that, for example, there is a very high probability of an immigrant from Latin America being placed in the South direction, but that does not mean that the cell cannot appear in any other direction. This is more on par with how cells multiply, as they certainly do not do it in an ordered manner. Ultimately, this makes our system non-deterministic.

Our algorithm queries data chronologically. For each query, it takes $\mathrm{N}$ people out of the dataset where all have the same place of birth. When we are showing native-borns for a certain decade, the algorithm first queries native-borns who are uniformly distributed around the radius they create. After the native-borns are queried, our algorithm starts querying immigrants and placing them according to their Gaussian probability model. When all data for a certain decade are finally

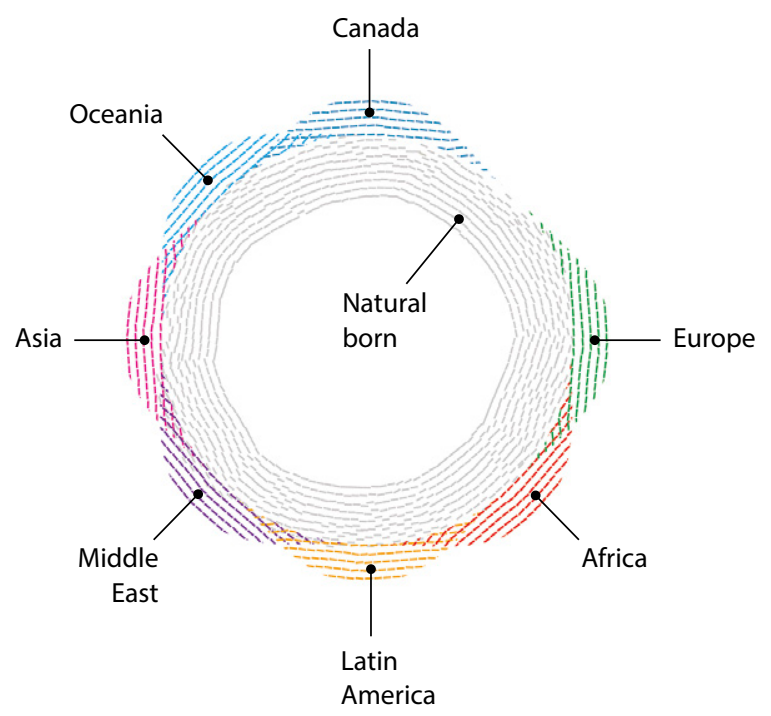

Figure 5. Places of origin were classified into seven cultural-geographical groups: Canada, Europe, Latin America, Asia, Oceania, Africa, and the Middle East. Colors were assigned accordingly. Each group corresponds to a certain orientation which is the average of the Gaussian distribution of probabilities attributed to it. 
queried, the time variable increases in the visualization, and data starts being queried for the next decade. In the case where we are only showing immigration, then any query of $\mathrm{N}$ people can be selected out of any group of immigrants. This creates fuzzy boundaries in immigration categories as will be seen in the results.

Although the algorithm places small circles in order to simulate the existence of cells, they are rendered as dashes. The orientation of these dashes follows the perimeter of the overall emerging shape and exists to give the impression of continuity, as if the image were made out of multiple curved paths (Figure 6).

\section{Results}

Both the approach previously described and the visual outcome of this work were the result of an iterative design process that was described in its early stages (Cruz, Wihbey, Ghael, Costa, \& Shibuya 2018). Our results can be illustrated first by showing one tree trunk generated for Massachusetts, for immigrants and native-borns, and for the period of 1790-2016. For this setup, we used one dash to represent 150 people. In Figure 7, for Massachusetts, it is possible to observe the waves of Canadian immigration together with the early waves of European immigration. The tree rings, which symbolize one decade each, are separated by white space. It is also possible to observe how in more recent years, the profile of immigration has diversified. The amalgam of cells results in a form that suggests how many people were born or came into Massachusetts over time. It configures a unique identity and enables viewers to observe the extent to which immigration contributed to the growth of the state in certain years.

Further, the U.S. can also be seen as forest of trees, as if each tree were a state. By using the same parameters as were employed in the case of Massachusetts, the visualization on Figure 8 shows this approach implemented for the fifty U.S. states, which are laid out geographically as a Dorling cartogram (Dorling 1996). At first glance, it is possible to observe which states grew more; and by looking at their shapes, it is possible to infer that some had less immigration than others. Immigration creates visible deposits of cells in certain directions, which creates irregular tree rings and complex forms. It can be observed that states with less immigration are the less diverse in terms of form. Labels for the states are positioned in such a way so that they curve around each of the states, providing a glancing and quick correspondence.

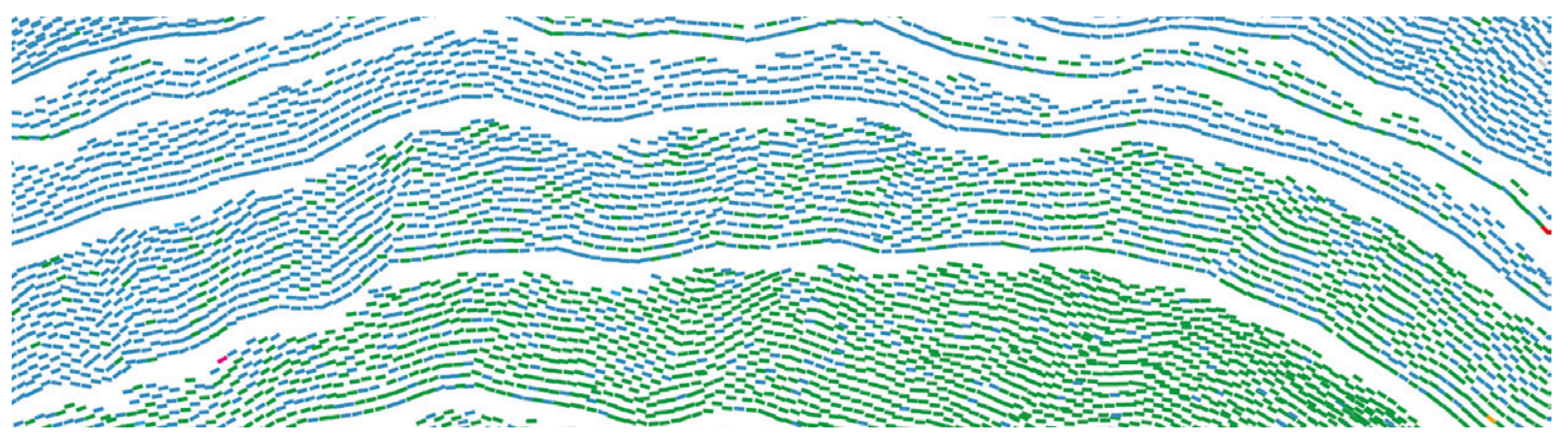

Figure 6. Detail showing dots rendered as dashes that follow the orientation of the lines. 


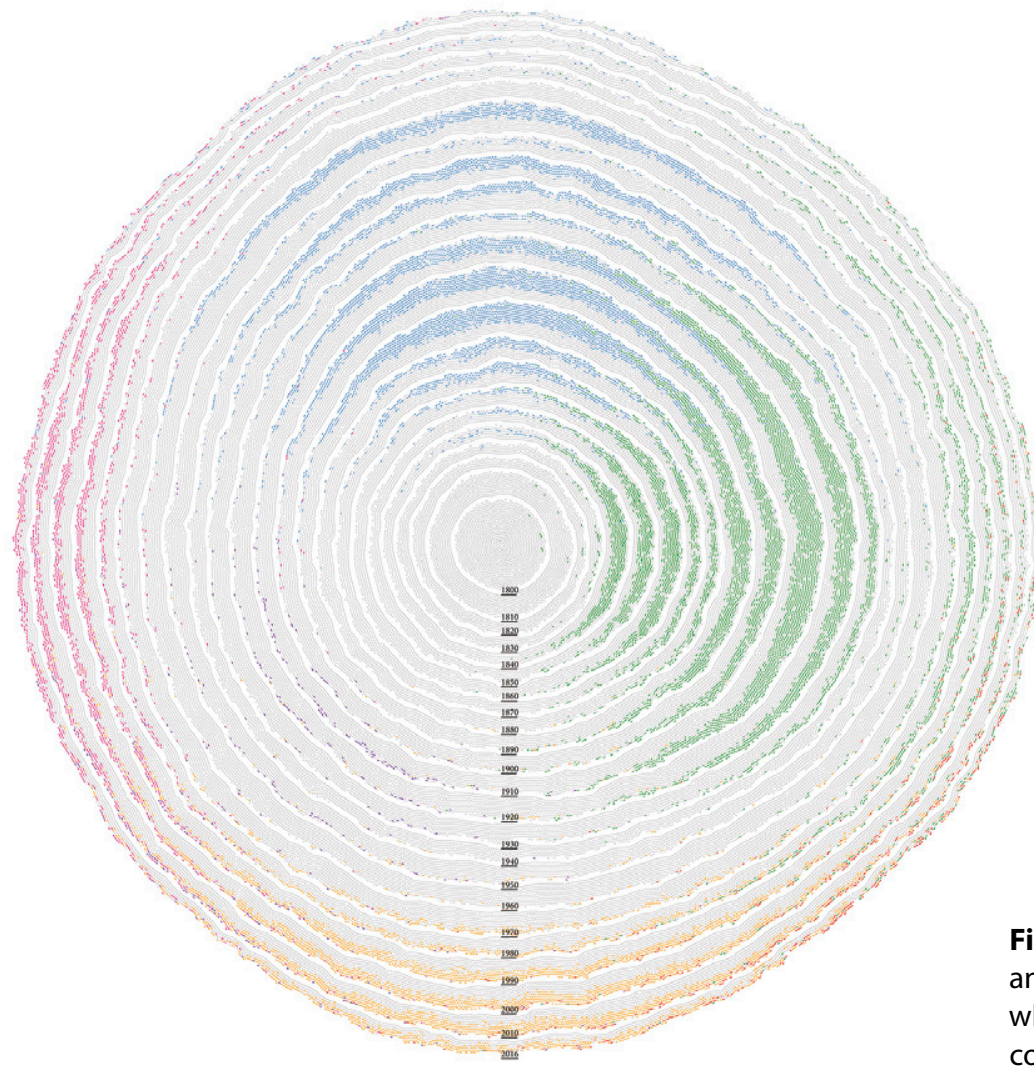

Figure 7. Generated tree trunk of immigration and native-borns, for Massachusetts (1760-2016) where each dash is 150 people. Each ring corresponds to a decade.
As mentioned, the second stage of this project focused on immigration only. For this stage, we started by generating a single tree trunk for the U.S. as a whole, where each dash is 100 people and one ring encompasses a single decade. This visualization can be seen in Figure 9, which depicts immigration from 1830 to 2016 . The years prior to 1830 were discarded because the influx of immigrants was not significant enough to be displayed at this scale. In Figure 9, several waves of immigration can be observed: the 1840 os and 188 os, when European immigrants came mainly from Northern and Western Europe; the influx of the early $1900 \mathrm{~s}$ that came mostly from Southern and Eastern Europe; immigration from Asia rose between 1970 and 2000; large-scale immigration from Latin America began in 1950 and lasted for half a century; and immigration from Africa only becomes visible in the twenty-first century. The rings are widest during times of economic prosperity, when immigration laws are often lax, and narrowest during periods of economic difficulty, conflict, and corresponding repressive immigration policies. One example of this is the period around the Second 
World War. This particular trunk can be observed in an animated way, growing from the data and displaying the immigrants and their places of origin that feed the tree: https://vimeo.com/276140430. The video runs for about 6 minutes and better illustrates the algorithmic process that produces the data-generated tree rings. The video plays with a subtle soundtrack of wind hitting on trees, reinforcing the metaphor while at the same time being reminiscent of ocean waves, and with that, waves of immigration.
This second stage of the project permitted storytelling exclusively about immigrants themselves, who in the prior stage were intermixed and in some sense diluted in the comparison with native-borns. We generated tree trunks for each of the states with these new parameters, using data relating to immigrants only. This array can be seen as a Dorling cartogram in Figure 10. Because we are rendering fewer people now, each dash represents 10 people. The forms that result have much more variation, and they confer a stronger identity for each state,

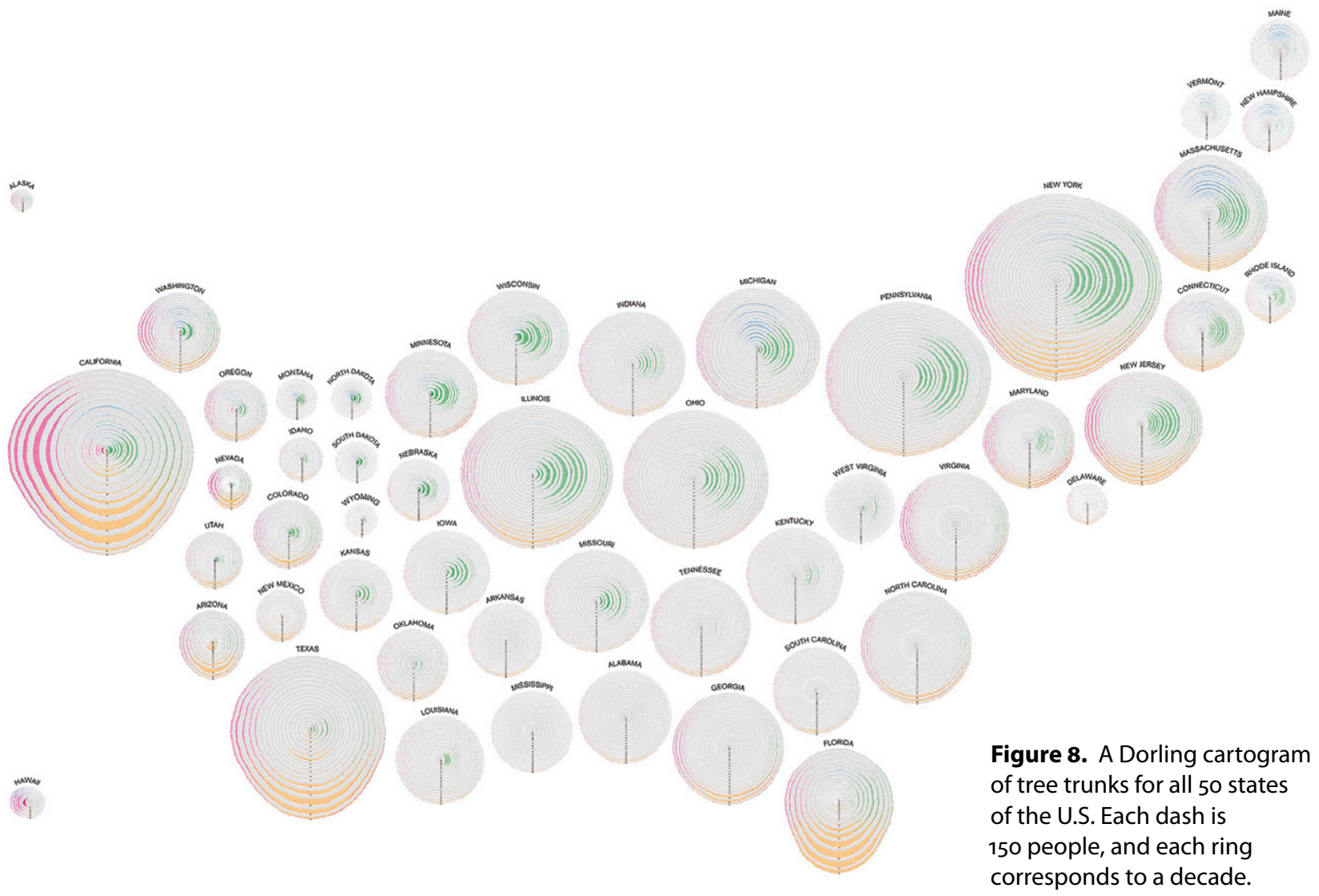


while at the same time being more diverse, colorful, and vibrant. These new forms, we hope, evince a celebratory tone around immigration, which is consistent with the genesis and motivating spirit of this project.

\section{Synthesis}

This work resulted in a series of visualizations of U.S. immigration in the form of tree trunks. In the first stage, the pattern of immigrants contributing to population growth was compared to population growth by virtue of native-borns. In the second stage, immigrants were visualized exclusively as a way to observe the intricacies and celebrate the existence of the American immigration phenomenon generally. Trees in nature can sometimes grow more in one particular direction, and we translated this natural pattern into our visualizations. This results in each state having its own form derived from data, as well as their own unique identity.

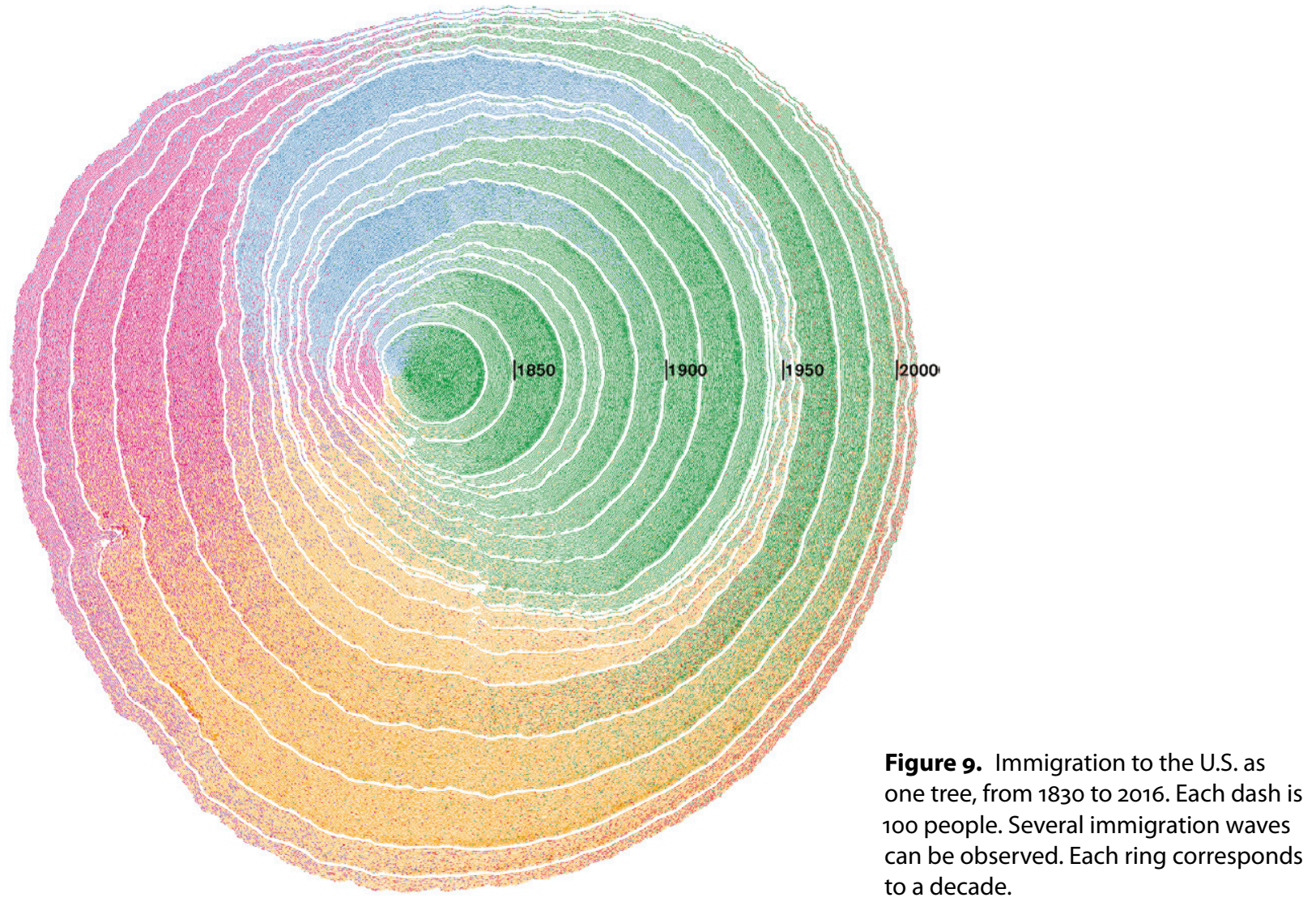




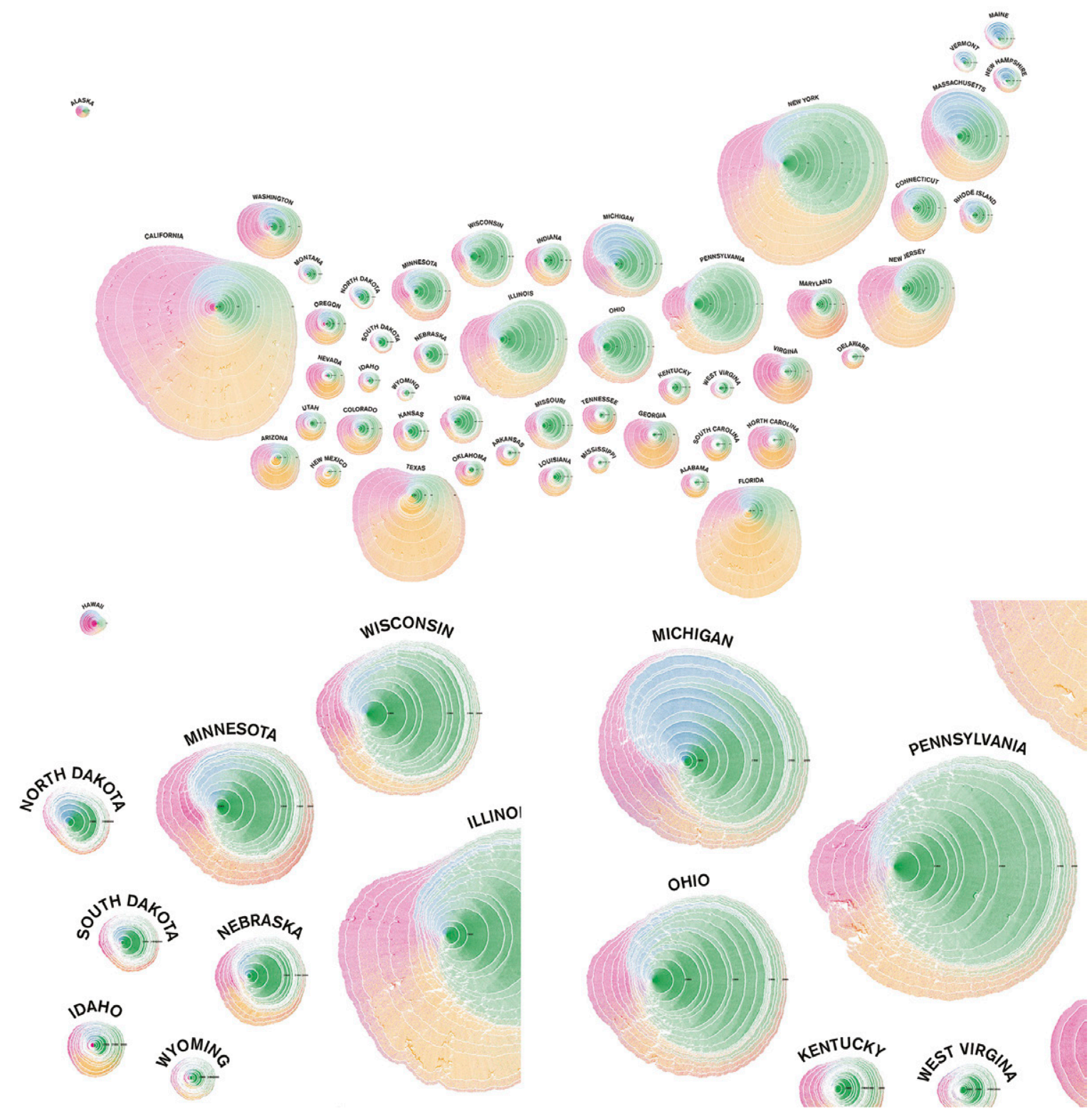

Figure 10. Immigration to the U.S. as tree trunks, one for each of the states, from 1830 to 2016. Each dash is 10 people. The states are laid out as a Dorling cartogram. Two closeups are presented. Each ring corresponds to a decade. 
The country can be envisioned as a forest of trees, providing additional layers of complexity that help tell the story of American immigration. Rings that are more skewed toward the East, for example, show more immigration from Europe, while rings skewed South show more immigration from Latin America. Some rings will be larger, some will be smaller; some will have complex shapes that represent waves of immigrants, and others will be more uniform due to low immigration numbers. The cells and rings in a tree are nature's own way of organizing information. The tree rings pack and encode a good degree of complexity that, nonetheless, is ordered in a certain way. This phenomenon supports the extraction of overall patterns, while enabling an observer to observe particularities of very thin rings or even to observe the ways in which dashes represent actual people.

We should repeat that, like countries, trees can be hundreds, even thousands, of years old. These cells grow at a very slow pace, and the pattern of growth influences the shape of the trunk. Just as these cells leave an informational mark in a tree in nature, incoming immigrants leave their mark in the country by contributing to the country's shape. This metaphor was chosen in order to communicate notions of inclusiveness, diversity, and the perennial. As importantly, the metaphor also provides a conceptual domain used to organize space for the effective presentation of information. These two aspects-the graphic-functional and the rhetorical-combine to position the metaphor as a way to interpret the immigration domain in terms of the tree-rings domain, and through that process, generate new meanings. In order to illustrate how our envisioned metaphoric translations can operate, we list below a few hypothesized thought processes:

- This trunk is skewed towards East, which means that a large number of immigrants came from Europe.

- This western ring is thicker than the others, representing a substantial influx of people during this decade.
- These four relatively colorless rings are layered 40 years before this influx, and give context to the sudden influx of migrants from Europe.

- The interior of the trunk is made out of people who came to the U.S. a long time ago, but the last layers of the trunk arrived less than 10 years ago.

- All of these cells, all of these people, are part of the same organism. They are all different, but all contributed to the organism's growth.

- A given migrant in an interior ring is a cell that came into the U.S. a long time ago, and yet it is still there; it left its mark in history.

- This tree has been made stronger and stronger by the incoming waves of immigration.

It should also be noted that, although the idea of diversity is embedded in this work, diversity in the U.S. in general has many more layers. The trajectories of Native Americans (indigenous or Indian peoples) and African Americans, who often descend from enslaved populations taken from Africa, are also an integral part of the story of the country. However, our work focused on immigrants only and thus did not include these groups in this story of diversity. Nevertheless, the research team involved in this project has sought to explore wider dynamics and narratives related to these groups that are vital to the more general U.S. story of diversity, but whose experiences are distinct from that of migrants who chose to come. The Census itself also has structural and historical problems from this perspective. Native Americans were largely not counted in federal censuses prior to 1900 ; slaves brought from Africa were counted as three-fifths of a person in the first census, and subsequent systems for counting were deeply flawed with respect to characterizing persons of mixed race (Wihbey, Jackson, Cruz, \& Welles, in press).

In an era of growing concern about the impact of restrictive immigration policy in the U.S., depicting this 
data using the highly figurative metaphor of tree rings can be a way to remind viewers that nations benefit from having long-term inflows of immigrants, whose vitality and ingenuity frequently fuels growth, while transforming communities and making them more diverse and inclusive.

\section{Submission date: 29 January, 2019}

Accepted date: 11 June, 2019

\section{References}

Cruz, P. (2015). Wrongfully right: applications of semantic figurative metaphors in information visualization (pp. 14-21). Presented at the IEEE VIS Arts Program Annotated Projects, Chicago. http://doi.org/10.13140/RG.2.1.1365.6727

Cruz, P., \& Machado, P. (2016). Pulsing Blood Vessels: A Figurative Approach to Traffic Visualization. IEEE Computer Graphics and Applications, 36(2), 16-21. http://doi.org/10.1109/MCG.2016.29

Cruz, P., Wihbey, J., Ghael, A., Costa, S., \& Shibuya, F. (2018). Process of simulating tree rings for immigration in the U.S. (pp. 1-17). Presented at the IEEE VIS Arts Program Annotated Projects, Berlin.

Donaldson, L. A., \& Singh, A. P. (2016). Reaction Wood. In Y. S. Kim, R. Funada, \& A. P. Singh (Eds.), Secondary Xylem Biology (pp. 93-110). Boston: Academic Press. http://doi.org/https:// doi.org/10.1016/B978-0-12-802185-9.00006-1

D'Efilippo, V., \& Ball, J. (2016). A rough guide to conflict. In The Infographic History of the World. Firefly Books.

Dorling, D. (1996). Area cartograms: their use and creation. Concepts and Techniques in Modern Geography, 59.

Fahn, A., Burley, J., Longman, K. A., \& Mariaux, A. (1981). Possible contributions of wood anatomy to the determination of the age of tropical trees. In F. H. Bormann \& G. Berlyn (Eds.), Age and growth rate of tropical trees: new directions for research (pp. 31-54). New Haven: Yale University.

Fruchterman, T. M. J., \& Reingold, E. M. (1991). Graph Drawing by Force-directed Placement. Software: Practice and Experience, 21(11), 1129-1164. http://doi.org/10.1002/spe.4380211102
Hinrichs, U., Schmidt, H., \& Carpendale, S. (2008). EMDialog: Bringing Information Visualization into the Museum. IEEE Transactions on Visualization and Computer Graphics, 14(6), 1181-1188. http://doi.org/10.1109/TVCG.2008.127

Kim, Y. S., Funada, R., \& Adya, P. S. (2016). Secondary Xylem Biology. Academic Press.

Manovich, L. (2011). What is visualisation? Visual Studies, 26(1), 36-49. http://doi.org/10.1080/1472586X.2011.548488

Ruggles, S., Flood, S., Goeken, R., Grover, J., Meyer, E., Pacas, J., \& Sobek, M. (2018). IPUMS USA: Version 8.o. Minneapolis. https://doi.org/10.18128/Do10.V8.0

Vande Moere, A., \& Lau, A. (2007). In-Formation Flocking: An Approach to Data Visualization Using Multi-agent Formation Behavior. Acal, 4828(Chapter 26), 292-304. http://doi.org/10.1007/978-3-540-76931-6_26

Wihbey, J. P., Jackson, S. J., Cruz, P. M., Welles, B. F. (2020). Visualizing diversity: Data deficiencies and semiotic strategies. In H. Kennedy \& M. Engebretsen (Eds.), Data Visualization in Society. Amsterdam: Amsterdam University Press.

\section{About the authors}

Pedro Cruz explores new metaphoric and figurative ways to visualize information. He is an Assistant Professor at Northeastern University in Information Design and Visualization. He holds a PhD in Information Science and Technology from the University

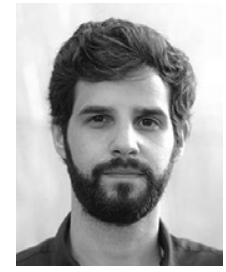
of Coimbra. He was a Visiting PhD Student at MIT Senseable City Lab in Cambridge and Singapore, working on visualization for cities. His work has been featured in several exhibitions around the world such as in the London Design Biennale, Ibero-American Biennale of Design, CES, MoMA's Talk to Me, SIGGRAPH CAF, and IEEE VIS Arts. He is the recipient of multiple awards in information design such as the KANTAR Information if Beautiful Award. He is faculty co-director of the Co-Laboratory for Data Impact at Northeastern. His work has been featured in specialized media such as Wired magazine, Fast Company, and National Geographic.

Email:p.cruz@northeastern.edu 
John Wihbey is an Assistant Professor of Journalism and Media Innovation at Northeastern University, where he heads the graduate programs in the School of Journalism. He is the author of The Social Fact: News and Knowledge in a Networked World (MIT Press, 2019). His research and teaching interests include the intersection of

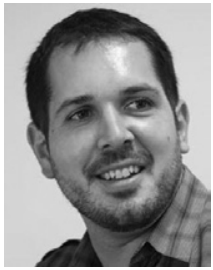
news and social media; misinformation and media literacy; the use of data and data visualization in journalism and communications; and issues of policy relating to news and social media platforms. He is faculty co-director of the Co-Laboratory for Data Impact. John is a faculty affiliate with the Global Resilience Institute and the NULab for Texts, Maps, and Networks. Having worked in newspapers, radio, and digital media, he helped found and oversee the Journalist's Resource project at Harvard's Shorenstein Center, where he continues to serve as a research associate.

Email: j.wihbey@northeastern.edu

Avni Ghael is a Computer Science graduate at Northeastern University, specializing in Web Technologies and Software Development. During her graduate studies, Avni took multiple internships and Research Assistantships at Northeastern where she strengthened her experience in database technologies and web development. She is currently a developer at Deloitte.

Email: avi.ghael@gmail.com

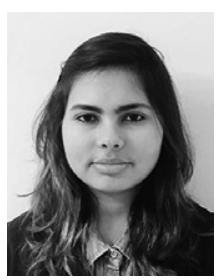

Felipe Shibuya is an ecologist and bioartist. He holds a PhD in Ecology and Conservation, from the Federal University of Paraná. He is currently an MFA student in Studio Art at the State University of New York at Buffalo, working at the intersection between biology and art. His current project involves the deconstruction of archetypes in species

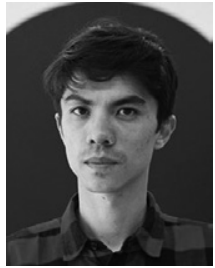
that became poetized by humans, such as hummingbirds. As a scientist-artist, he explores different forms of life, from bacteria to trees, using different methods, from microbiological culture to videos. He has presented his work at several venues, such as the School of Visual Arts (New York) and at the Universidad Nacional Autónoma de México (Mexico City).

Email: f.santoss@buffalo.edu

\section{Steve Costa has an MFA in Information} Design and Visualization from Northeastern University. He holds a BFA in Graphic Design from the same university. In 2019 he received an Art and Design Department Award for best thesis in information design on Government Dashboards. He is a designer specializing in brand identity and data visualization. He aims to help the public by aiding government agencies in their communications and data representations. Currently he is a Senior Graphic Designer at the Boston Planning \& Development Agency.

Email: stephentcosta@gmail.com 